\title{
Peripheral inflammatory biomarkers in Alzheimer's disease: a brief review
}

\author{
Jong-Chan Park ${ }^{\#}$, Sun-Ho Han ${ }^{\#}$ E Inhee Mook-Jung ${ }^{*}$ \\ Department of Biomedical Sciences, College of Medicine, Seoul National University, Seoul 03080, Korea
}

\begin{abstract}
Alzheimer's disease (AD) is a chronic neurodegenerative disease characterized by the accumulation of amyloid plaques and neurofibrillary tangles in the brain. The AD pathophysiology entails chronic inflammation involving innate immune cells including microglia, astrocytes, and other peripheral blood cells. Inflammatory mediators such as cytokines and complements are also linked to AD pathogenesis. Despite increasing evidence supporting the association between abnormal inflammation and $A D$, no well-established inflammatory biomarkers are currently available for AD. Since many reports have shown that abnormal inflammation precedes the outbreak of the disease, non-invasive and readily available peripheral inflammatory biomarkers should be considered as possible biomarkers for early diagnosis of $\mathrm{AD}$. In this minireview, we introduce the peripheral biomarker candidates related to abnormal inflammation in AD and discuss their possible molecular mechanisms. Furthermore, we also summarize the current state of inflammatory biomarker research in clinical practice and molecular diagnostics. We believe this review will provide new insights into biomarker candidates for the early diagnosis of $A D$ with systemic relevance to inflammation during $A D$ pathogenesis. [BMB Reports 2020; 53(1): 10-19]
\end{abstract}

\section{INTRODUCTION}

Alzheimer's disease (AD) is one of the most prevalent neurodegenerative diseases with progressive and irreversible pathogenesis. Numerous studies have suggested that $A D$ pathogenesis is associated with not only abnormal cerebral function but also changes in central and peripheral immune system. Specifically, it is characterized by neuroinflammation $(1,2)$. Activated microglia are one of the early hallmarks of AD

*Corresponding author. Tel: +82-2-740-8245; Fax: +82-2-3672-7352; E-mail: inhee@snu.ac.kr

${ }^{\text {"}}$ These authors contributed equally to this work.

https://doi.org/10.5483/BMBRep.2020.53.1.309

Received 1 December 2019

Keywords: Alzheimer's disease, Cytokine, Immune Cell, Inflammation, Peripheral blood biomarker pathogenesis (3). Numerous reports have shown over-activation of microglia $(4,5)$, activated complement system (6), increased production of cytokines (7) and chemokines during AD pathogenesis, and some of them were suggested as diagnostic biomarkers $(8,9)$. Recently, immune-related pathophysiological mechanisms were discovered during AD pathogenesis, including innate immune cell infiltration and altered brain-gut axis as well as microglial and astrocyte activation $(10,11)$ which play a role in peripheral immune dynamics and act as possible biomarkers for disease.

Various inflammatory molecules are affected by AD pathogenesis, with abnormal levels in different brain regions $(12,13)$. Amyloid beta $(A \beta)$ and amyloid precursor protein (APP) induce cytokine and chemokine release from microglia, astrocytes, and neurons; chemokine and cytokines also promote the expression and deposition of amyloid beta, which activates the vicious cycle (14). Furthermore, neuroinflammation may be an early event and plays a critical role in tau pathology, characterized by microglial activation preceding tau tangle formation. Immunosuppression ameliorated tau pathology in P301S transgenic mice (15). Also, peripheral levels of inflammation-related cytokines change during $A D$ pathogenesis and are significantly correlated with disease progression (16-18). Therefore, the crosstalk between abnormal events in the central compartment, involving neuronal dysfunction and microglial activation, and peripheral immune system is critical for the understanding of the mechanism of AD pathogenesis (19).

In this review, we discuss various inflammation-related molecules, especially those altered at the peripheral level, and suggested their potential role as risk factors, diagnostic markers and therapeutic targets in AD. Even though it is ambiguous whether inflammatory cytokines are related to the cause or effect of $A D$ pathogenesis, a better understanding of these molecules during $A D$ pathogenesis can lead to a therapeutic breakthrough against AD.

\section{PRO-INFLAMMATORY CYTOKINES IN AD}

IL-1

IL-1 is a pro-inflammatory cytokine, which elicits diverse systemic effects (20). IL-1 was the first cytokine whose actions on the brain were identified $(21,22)$. The two isoforms of IL-1 
were identified as IL-1 $\alpha$ and IL-1 $\beta$ encoded by two different genes IL-1A and IL-1B, respectively (23).

Elevated IL-1 was reported not only in acute injuries but also in a number of chronic neurodegenerative disorders $(24,25)$. IL-1 levels are markedly overexpressed in the brains of patients with AD (26), mainly in microglia (26). Increased IL-1 level is related to $A \beta$ plaque formation, tau phosphorylation, and neurofibrillary tangle formation via activation of MAPK-P38 (27). Also, IL-1 has been reported to modulate neurons in hippocampus (28) and trigger age-related impairment of long-term potentiation (29). In vitro and in vivo experiments demonstrated that the secreted BAPP induced IL-1 overexpression from microglia, which suppressed cholinergic function by enhancing the expression and activity of acetylcholinesterase (AChE) (30), suggesting a possible mechanistic event relevant to cholinergic dysfunction in AD. In a recent report, peripheral changes in blood AChE level were also detected in cognitively normal individuals with cerebral amyloid deposition (31). This phenomenon might be possibly associated with altered cytokine release, including IL-1, during $\mathrm{AD}$ pathogenesis. Furthermore, several genetic variants in IL-1 are associated with an increased risk for AD depending on the ethnic groups or ApoE genotypes $(32,33)$, which reinforce the strong relationship between IL-1 and AD pathogenesis. Additionally, IL-1 interacts with several products of known genetic risk factors for $A D$, including $A p o E, \alpha 2$-macroglobulin, $\alpha 1$-antichymotrypsin and $\beta$ APP (33), suggesting implications for $\mathrm{AD}$ pathogenesis.

Increased IL-1 $\beta$ was detected in the blood of patients with AD $(7,34-38)$. Increased levels of both IL-1 $\alpha$ and IL-1 $\beta$ have also been reported in the serum of AD patients; however, no changes in cytokine levels were detected in the serum of patients with mild cognitive impairment $(\mathrm{MCl})$, compared with healthy control (39). Further, evidence is not sufficient to suggest that the elevated plasma IL-1 level in AD was caused by peripheral immune activation during $A D$ pathogenesis (35). Instead, the increased levels of circulating IL-1 might be attributed to the central alteration during AD (35). Unfortunately, in other studies, no differences in blood IL-1 levels have been detected between controls and AD patients (40-43). Results of blood IL-1 level in $\mathrm{MCl}$ are also disputed, suggesting an increase compared with healthy controls in a few studies but not others $(37,39)$. These contradictory results might be attributed to differences in the sensitivity of diagnostic and screening tools, low levels of IL-1 in the blood or altered IL-1 level in only a subpopulation or specific stage of AD patients.

\section{IL-6}

IL-6 levels are elevated in the brains of AD patients (44) and are linked to diffuse plaques representing the early stage of plaque formation (45). A $\beta$ has been shown to induce IL-6 expression in microglia and astrocyte culture system (46). Significant correlations between IL- 6 levels in CSF and in matched blood samples were observed $(47,48)$, and the elevated level of plasma IL-6 was detected in mild cases of AD (48). AD-related increase in blood IL-6 level has been reported in other studies as well $(7,35,38,48,49)$.

However, other studies failed to show consistent results of increased IL-6 levels in the blood $(40,43,50,51), \operatorname{CSF}(7,40$, $52,53)$ or brain $(40)$. Further, decreased IL-6 levels were reported in serum $(54)$ and in $\operatorname{CSF}(54,55)$ of $A D$ patients. In addition, lipopolysaccharide-induced IL-6 release from blood cells was significantly reduced in moderate AD (36). These conflicting results involving peripheral cytokine levels, including levels of IL-6 and IL-1, dispute the role of cytokines in $\mathrm{AD}$ pathogenesis. Nonetheless, reports suggesting the modulation of AD susceptibility based on specific IL-1 or IL-6 gene polymorphism demonstrate the important role played by these cytokines during $A D$ pathogenesis (56-58). Especially, specific IL-1 gene polymorphisms are strongly correlated with the increased risk for AD possibly via altered modulation of IL-1-induced neurodegeneration (58).

\section{TNF- $\alpha$}

The pro-inflammatory cytokine tumor necrosis factor (TNF) $\alpha$ is a critical mediator of inflammatory response in diverse tissues and is secreted by diverse cell types including astrocytes and microglia in brain (53). This cytokine is secreted during both acute and chronic systemic inflammation involving immune system and the brain (59).

TNF- $\alpha$ is one of the most well-defined cytokines during AD pathogenesis because TNF- $\alpha$ level is strongly correlated with cognitive decline, neuronal toxicity and cerebral apoptosis. Increased TNF- $\alpha$ levels were found in different anatomic locations of brain in AD patients (60). Also, mild-to-severe AD patients with increased serum TNF- $\alpha$ level showed a 2 -fold increase in the rate of cognitive decline and a high baseline TNF- $\alpha$ level was related to a 4 -fold increase in cognitive decline (16).

Evidence suggests that the pathological hallmark $A \beta$ induces microglial activation and TNF- $\alpha$ release (61) and this TNF$\alpha$-related inflammation plays a deleterious role in neuronal death (62). TNF- $\alpha$ release from microglia, astrocytes and neurons during $A D$ pathogenesis is a chronic event (63) and altered levels of TNF- $\alpha$ in the brain might induce changes in the peripheral levels of TNF- $\alpha$. Numerous reports suggest evidences for alteration of TNF- $\alpha$ level in biological fluids from AD patients (64). In CSF, an average 25-fold increase of TNF- $\alpha$ level has been reported in AD compared with control (65). In the periphery, the increased levels of blood TNF- $\alpha$ have been widely reported in various studies including $\mathrm{MCl}$ and $A D$ patients and were strongly associated with the rate of cognitive decline $(7,16,43,66-68)$. Meanwhile, no changes in TNF- $\alpha$ level were reported in another study using serum $(42,53)$ or $\operatorname{CSF}(7,40,52)$. Instead, a lower TNF- $\alpha$ level has been reported in the blood of $\mathrm{AD}$ patients compared with age-matched control subjects in a study of patients with earlyas well as late-onset AD (34). Also, TNF- $\alpha$ release from blood 
cell following lipopolysaccharide exposure was shown to decrease significantly in moderate AD (36), Probably, the blood TNF- $\alpha$ level may be associated with a wide range of individual variation and reflect disease-dependent alteration (64).

\section{IL-12}

IL-12 is a proinflammatory cytokine secreted by activated macrophages, monocytes, and glial cells via Toll-like receptor activation $(69,70)$ and its dual potential for pro- and antiinflammation activity has been shown in a previous study (71). During AD pathogenesis, the IL-12 level in CSF is reduced in AD patients compared with neurological control patients (72). Also, another study reported increased IL-12 levels in the blood of patients with mild and moderate AD (7) while severe AD suppressed plasma IL-12 levels (18), which might possibly suggest the potential for dual activities. A recent report demonstrated the inhibition of IL-12/IL-23 pathway via genetic ablation or pharmacological manipulation resulting in a drastic reduction of cerebral amyloid pathology and cognitive deficit (73). Indirect evidence supporting the role of IL-12 during AD pathogenesis is based on $A \beta$ immunization in a mouse model of $A D$ with reduced amyloid burden along with decreased expression of the IL-12R $\beta 1$ receptor in T cells $(73,74)$. All these results suggest the potential role of $\mathrm{IL}-12$ in neurodegenerative disease including AD.

\section{ANTI-INFLAMMATORY CYTOKINES IN AD}

\section{IL-4}

IL-4 is an anti-inflammatory cytokine neutralizing the pro-inflammatory action. IL-4 inhibits the secretion of IL-1 $\beta$, IL- 6 and TNF- $\alpha$ by activated monocytes (75). Despite the absence of differences between $A D$ and control subjects in terms of peripheral concentration of IL-4 (7), the blood IL-4 level is closely associated with cognitive decline in $A D$ (17). In this study, AD patients with rapid cognitive decline showed a significant increase in blood IL-4 level compared with those representing a slow decline. More interestingly, the peripheral levels of IL-4 and IL-1 $\beta$ are altered by treatment with acetylcholinesterase inhibitor (AChEl), showing increased IL-4 and decreased IL-1 $\beta(76,77)$. Recently, it has been reported that $\mathrm{AChEl-treated} \mathrm{AD}$ patients showed an increase in the peripheral levels of $\mathrm{AChE}$, demonstrating the connection between central $\mathrm{AChEI}$ action and peripheral synchronization (31). Therefore, it is possible that the beneficial effects of AChEl treatment in AD patients may not be limited to the central compartment but also mediated via peripheral changes in inflammation mediated by IL-1 via IL-4.

\section{IL-10}

IL-10 is an anti-inflammatory cytokine, which reduces inflammation during AD pathogenesis. Increased IL-10 level has been reported in the brains of patients with neurological diseases including Alzheimer's disease (78) and also in the serum of patients with $A D$ and vascular dementia compared with healthy controls (38) while no change was detected in $A D$ in another study $(7,43)$. Peripheral IL-10 is another candidate biomarker of disease progression and is strongly associated with clinical status and imaging parameters of disease severity (17). Similar to IL-4, AD patients with increased levels of blood IL-10 exhibit rapid cognitive decline compared with those demonstrating a slow decline (17). Also, the IL-10 level was associated with brain atrophy in MRI measurements during AD (17). Possibly, the anti-inflammatory cytokines, including IL-4 and IL-10, may be regarded as a compensatory mechanism during pathogenesis. A strong compensatory mechanism may imply severe pathological lesions.

\section{THE ROLE OF INTESTINAL CYTOKINES (BRAIN-GUT AXIS) IN AD}

Gut microbiota play an important role in host metabolism and physiology and influences not only the immune system but also the nervous system related to brain development and cognitive function $(79,80)$. Several recent studies have demonstrated the importance of gut microbiota composition in $\mathrm{AD}$ pathogenesis and the role of gut microbiota has emerged as the new field in AD-related neurodegeneration (81). Furthermore, microbiota in gut play a key role in peripheral immune cell activation and cytokine secretion during the inflammatory cascade in the periphery and central nervous system-related disruption of gut barrier and blood-brain barrier (81). Therefore, neuroscientists have expanded the scope of studies investigating neuroinflammation in brain to include systemic inflammation involving the brain-gut axis during $A D$ pathogenesis.

The mouse model of $A D$ indicates altered composition of gut microbiota compared with that of healthy wild-type mice, in addition to loss of gut epithelial barrier integrity, chronic systemic and intestinal inflammation (11). A previous study demonstrated that the direct transfer of fecal microbiota from wild-type to AD mouse models ameliorated not only amyloid and tau pathology but also cognitive dysfunction, and the underlying mechanism entailed recovery of intestinal macrophage activity and circulating Ly6C + monocytes (11). Another study showed that the altered composition of gut microbiota via probiotic formulation in $A D$ mouse models reduced the plasma levels of pro-inflammatory cytokines, IL-1 $\alpha$, IL-1 $\beta$, IL-2, IL-12, IFN $\gamma$ and TNF- $\alpha$, which were higher in $\mathrm{AD}$ mouse models compared with levels in healthy wild-type mice (82). Also, probiotic treatment increased the levels of anti-inflammatory cytokines, including IL-4, IL-6, G-CSF, GM-CSF, and downregulated inflammatory cytokines. Partial restoration of impaired neuronal proteolytic pathways and decreased cognitive impairment suggest that inflammationrelated cytokines are important modulators of brain gut axis 
during $A D$ pathogenesis.

\section{POTENTIAL USE OF BLOOD IMMUNE CELLS AS BIOMARKERS FOR AD}

Peripheral changes in blood circulation have been known to impact brain function. However, due to the failure of various protein-based circulating blood biomarkers, recent studies investigated cell-based biomarkers. Blood immune cells are potential biomarkers in AD. These white blood cells are classified according to cell lineage (myeloid or lymphoid cells) and are further divided into specific cell types such as T lymphocytes, B lymphocytes, and natural killer cells derived from the common lymphoid progenitor cells, and monocytes, eosinophils, neutrophils, basophils, erythrocytes, mast cells, and thrombocytes originating from common myeloid progenitor cells (83). Accumulating evidence suggests that these immune cells play an important role in $A D$ pathogenesis, for e.g., migration of neutrophils traversing the BBB into the brain targeting amyloid plaques (10), recruitment of monocytes/ macrophages via CCL2 or CX3CL1 to the sites of inflammatory response (84), and changes in regulatory T lymphocyte profiles (85) and amyloid-beta peptide autoantibodies from B lymphocytes (86). We discuss the potential immune cell-associated blood biomarkers to provide novel insight into blood-based biomarkers beyond the circulating biomarker candidates reported previously.

\section{Changes in the peripheral profile of blood immune cells}

The changes in blood cell profile of $A D$ have yet to be fully investigated; however, several reports showed altered peripheral profile of blood cells in AD. Chen et al. (2017) reported that the blood cell population was associated with $\mathrm{AD}$ pathogenesis in $92 \mathrm{AD}$ patients and 84 cognitively normal controls (age and sex matched). The population of lymphocytes and basophils decreased in AD patients compared with normal controls; however, there were no changes in the levels of other white blood cells such as neutrophils, monocytes, and eosinophils (87). Another study reported similar results suggesting that the population of resting regulatory $T$ lymphocytes $\left(T_{\text {reg }}\right)$ decreased significantly in the AD group compared with that of cognitively normal group (85). Although these studies did not reveal any changes in myeloid cell profile except for basophils, other studies showed an increase in the number of monocytes in the blood (88) and decreased CCR2 + monocytes (89) in $A D$ brain, suggesting that monocytes are possible $A D$ biomarker candidates. Furthermore, Richartz-Salzburger et al. (2007) also reported that T and B lymphocytes are significantly downregulated in subjects with clinically diagnosed $A D$ compared with cognitively normal participants (90). Even if few studies reported the diagnostic sensitivity or specificity of blood immune cell population for $A D$, the published studies demonstrate the possible role of peripheral immune cells as one of the candidate biomarkers for $\mathrm{AD}$.

\section{COMPLEMENTS AS BIOMARKERS FOR AD}

The complement system plays an important role in innate immune response (91) and in the regulation of $A D$ risk factors inducing neuronal death (92). A preponderance of evidence derived from genetic, proteomic, and immunological studies suggests that the system is relevant to $A D$ pathogenesis.

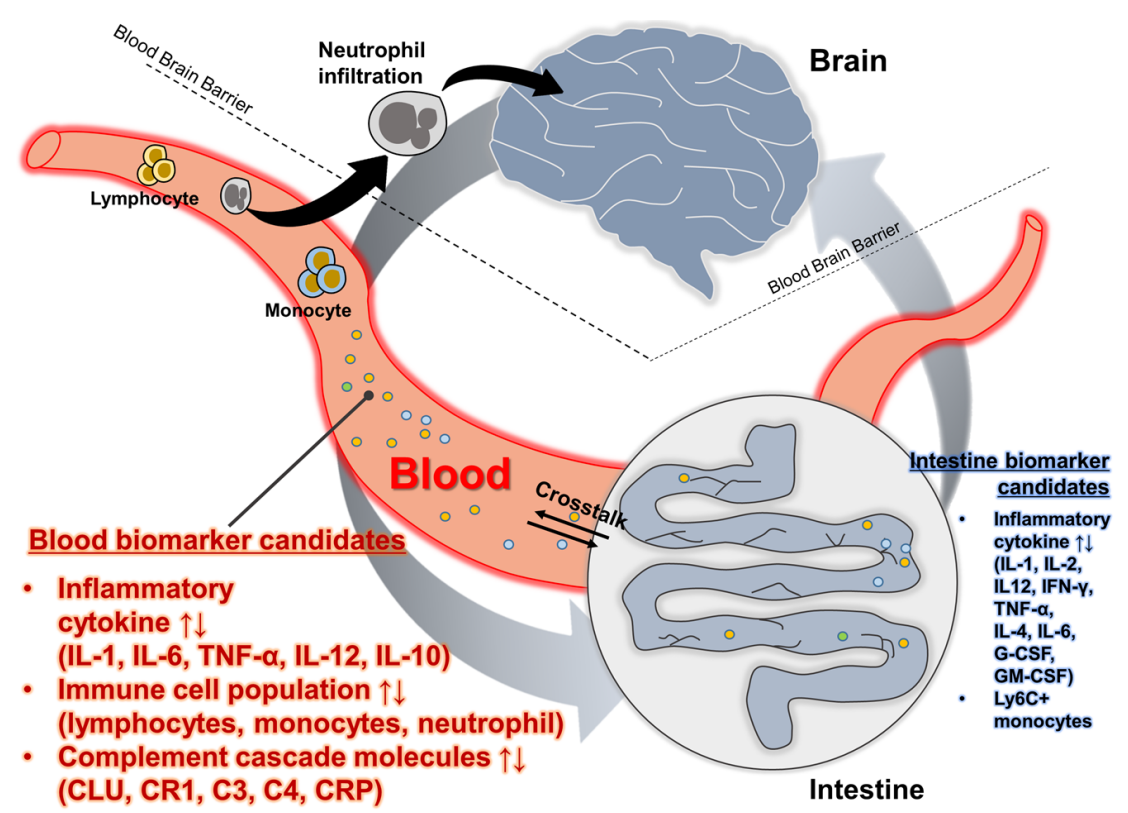

Fig. 1. Graphical summary of peripheral inflammatory biomarker candidates. 
Genetic profiles determined using genome-wide association studies (GWAS) reveal the relationship between $A D$ risk and genes associated with the complement cascade, such as single nucleotide polymorphisms (SNP) involving clusterin (CLU) and complement receptor 1 (CR1) $(93,94)$. C1q and C3 components bind to amyloid beta plaques and activate the classical and alternative complement pathways $(92,95)$. Previous studies have shown that the levels of complement system components in plasma in $\mathrm{AD}$ were altered compared with that of normal controls, such as complement factor $\mathrm{H}(\mathrm{FH})$, clusterin, plasma factor I (FI), C4d, iC3b, Bb, and iC3b (96-99). Here, we discuss the role of reliable blood-based biomarkers using the complement cascade components.

\section{Genetic profile of the complement system}

Emerging evidence derived from genetic studies suggest that the components of the complement cascade are strongly associated with AD pathophysiology (100-102). Recent GWAS demonstrated the existence of many SNPs for genes associated with the complement pathway related to $A D$, such as CLU, CR1, SERPINA3, CRP, C2, CFH, C3, and C4 (91, 102-105).
Especially, the CLU, also known as apolipoprotein J (ApoJ), and CR1 genes are the major risk genes associated with late-onset $\mathrm{AD}$ (LOAD) $(102,106)$. The three representative SNPs in the Clu gene include rs11136000, rs2279590, and rs9331888 (105). Interestingly, the rs 11136000 SNP is observed in Asian and Caucasian populations, and the two populations exhibit similar genetic risk (Asian, $\mathrm{OR}=0.85$; Caucasian, $\mathrm{OR}$ $=0.82)(107,108)$. The rs2279590 SNP showed significant correlation with the degree of brain amyloid plaques (109), and the rs9331888 polymorphism is linked to the levels of CLU in blood plasma (110). The CR1 gene, which is mainly expressed in human erythrocytes, encodes CR1 protein to facilitate amyloid-beta clearance mediated via C3b (111). The major polymorphisms of CR1 gene include rs6656401, rs4844609, and rs3818361 $(102,112)$. Several studies have investigated the specific roles of these SNPs.

\section{Plasma levels of complement cascade-related molecules} Since both CLU and CR1 are the major risk factors involved in $A D$, they play key roles in neuro-inflammation and innate immunity (91). The relationship between CLU protein and

Table 1. Altered levels of candidate biomarkers

\begin{tabular}{|c|c|c|c|c|}
\hline Biomarker (blood) & $\begin{array}{l}\text { Up regulation } \\
\text { (reference no.) }\end{array}$ & $\begin{array}{l}\text { Down regulation } \\
\text { (reference no.) }\end{array}$ & $\begin{array}{l}\text { No regulation } \\
\text { (reference no.) }\end{array}$ & Superiority \\
\hline IL-1 & $(7,34-39)$ & - & $(40-43)$ & $\mathrm{Up}+\mathrm{No}$ \\
\hline IL-6 & $(7,35,38,48,49)$ & (54) & $(43,50,51)$ & $\mathrm{Up}+\mathrm{No}+$ Down \\
\hline TNF- $\alpha$ & $(7,16,43,66-68)$ & (34) & $(42,53)$ & $\mathrm{Up}+\mathrm{No}+$ Down \\
\hline IL-12 & $(7)$ & (18) & - & Up + Down \\
\hline IL-4 & & & (7) & No \\
\hline IL-10 & & & $(7,43)$ & No \\
\hline Lymphocyte & - & $(85,90)$ & - & Down \\
\hline Monocyte & (88) (89) & - & (87) & $\mathrm{Up}+\mathrm{No}$ \\
\hline CLU & $(114,115)$ & - & - & Up \\
\hline CR1 & - & - & $(112,116)$ & No \\
\hline $\mathrm{C} 3$ & (99) & - & - & Up \\
\hline $\mathrm{C} 4$ & (118) & - & - & Up \\
\hline CRP & $(120-122)$ & (119) & - & Up + Down \\
\hline Biomarker (intestine) & \multicolumn{3}{|c|}{ Up \& Down changes based on probiotic formulation or FMT in AD mouse model } & Reference no. \\
\hline IL-1 & & Down & & (82) \\
\hline IL-2 & & Down & & (82) \\
\hline IL-12 & & Down & & (82) \\
\hline $\mathrm{IFN}-\gamma$ & & Down & & $(82)$ \\
\hline TNF- $\alpha$ & & Down & & (82) \\
\hline IL-4 & & Up & & $(82)$ \\
\hline IL-6 & & Up & & (82) \\
\hline G-CSF & & Up & & (82) \\
\hline GM-CSF & & Up & & $(82)$ \\
\hline 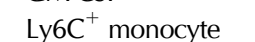 & & Down & & (11) \\
\hline
\end{tabular}

Abbreviations: up, up regulation; down, down regulation; no, no regulation; FMT, fecal microbiota transplant. 
amyloid-beta peptide has been reported, such as the ability of CLU in amyloid beta clearance (113). Blood CLU levels were drastically increased in AD patients compared with cognitively normal controls (114), and similar results were published by another group suggesting that the plasma levels of CLU increased in participants with cognitive decline and in $A D$ patients in longitudinal follow-up, but not in CSF samples (115). Plasma CR1 levels were not related to the clinical diagnosis of AD. However, the levels of rs4844609 and rs6656401 SNP carriers were slightly increased compared with that of CR1 without the SNPs $(112,116)$. Cerebrospinal fluid (CSF) levels of CR1 also did not show any differences between the different cognitive stages of $A D$ (117). Plasma levels of $C 3$ and C4 were not much in evidence; however, Bennett el al., (2012) showed that the levels of C4a protein were enhanced in AD participants compared with cognitively normal subjects. Thambisetty et al. (2011) reported the association of C3 and C3a protein with brain atrophy in $A D$ subjects $(99,118)$. Plasma C-reactive protein (CRP) levels are relatively well known, but there have been some contradictory results suggesting the reduced levels of plasma CRP in AD (119). However, other studies suggest higher plasma levels of CRP in AD or subjects with cognitive decline (120-122).

\section{CONCLUSION}

Here, we discussed a variety of inflammatory mediators such as pro- and anti-inflammatory cytokines, intestinal cytokines, peripheral immune cells, and complement cascade-related molecules (Fig. 1 and Table 1). Reports regarding peripheral cytokine levels show very inconsistent results in various studies. The studies involving IL-1, IL- 6 and TNF- $\alpha$ need to be validated using large-scale population cohorts. Recently, a combination of protease and phosphatase inhibitors has been used to detect low levels of blood biomarkers in AD (123). Effective detection of low levels of blood biomarkers might greatly facilitate the detection of low levels of cytokines in the blood. Furthermore, AD pathogenesis can alter diverse physiological systems, including neuronal function, brain structure, immune dynamics, brain-gut axis, and metabolism. Therefore, a single biomarker may not be adequate to delineate the pathophysiology of AD completely. Instead, a combination of multiple markers representing different stage of disease progression is the best strategy. Immune cell profiles and complement cascade play a potential role in providing novel insight into blood-based biomarkers compared with circulating protein biomarkers reported previously, although further validation is needed. Although the use of inflammatory mediators as peripheral $A D$ biomarkers has yet to be established, further studies are needed given the link between inflammation and AD.

\section{ACKNOWLEDGEMENTS}

This work was supported by a grant of the Korea Health technology R\&D Project through the Korea Health Industry Development Institute (KHIDI), funded by the Ministry of Health \& Welfare, Republic of Korea (HI18C0630 and HI19C1132) for I. Mook-Jung and a grant from NRF (NRF-2019R1I1A1A01063525) for S. Han.

\section{CONFLICTS OF INTEREST}

The authors have no conflicting interests.

\section{REFERENCES}

1. Heneka MT, Carson MJ, El Khoury J et al (2015) Neuroinflammation in Alzheimer's disease. Lancet Neurol 14, 388-405

2. Han SH, Park JC and Mook-Jung I (2016) Amyloid beta-interacting partners in Alzheimer's disease: From accomplices to possible therapeutic targets. Prog Neurobiol 137, 17-38

3. Hansen DV, Hanson JE and Sheng M (2018) Microglia in Alzheimer's disease. J Cell Biol 217, 459-472

4. Cagnin A, Brooks DJ, Kennedy AM et al (2001) In-vivo measurement of activated microglia in dementia. Lancet 358, 461-467

5. Baik SH, Kang S, Lee W et al (2019) A Breakdown in Metabolic Reprogramming Causes Microglia Dysfunction in Alzheimer's Disease. Cell Metab 30, 493-507 e496

6. Yasojima K, Schwab C, McGeer EG and McGeer PL (1999) Up-regulated production and activation of the complement system in Alzheimer's disease brain. Am J Pathol 154, 927-936

7. Swardfager W, Lanctot K, Rothenburg L, Wong A, Cappell J and Herrmann N (2010) A meta-analysis of cytokines in Alzheimer's disease. Biol Psychiatry 68, 930-941

8. Correa JD, Starling D, Teixeira AL, Caramelli P and Silva TA (2011) Chemokines in CSF of Alzheimer's disease patients. Arq Neuropsiquiatr 69, 455-459

9. Sui X, Liu J and Yang X (2014) Cerebrospinal fluid biomarkers of Alzheimer's disease. Neurosci Bull 30, 233-242

10. Baik SH, Cha MY, Hyun YM et al (2014) Migration of neutrophils targeting amyloid plaques in Alzheimer's disease mouse model. Neurobiol Aging 35, 1286-1292

11. Kim MS, Kim Y, Choi $\mathrm{H}$ et al (2020) Transfer of a healthy microbiota reduces amyloid and tau pathology in an Alzheimer's disease animal model. Gut 69, 283-294

12. Akiyama H, Barger S, Barnum S et al (2000) Inflammation and Alzheimer's disease. Neurobiol Aging 21, 383-421

13. Wilson CJ, Finch CE and Cohen HJ (2002) Cytokines and cognition-the case for a head-to-toe inflammatory paradigm. J Am Geriatr Soc 50, 2041-2056

14. Solfrizzi V, D'Introno A, Colacicco AM et al (2006) Circulating biomarkers of cognitive decline and 
dementia. Clin Chim Acta 364, 91-112

15. Metcalfe MJ and Figueiredo-Pereira ME (2010) Relationship between tau pathology and neuroinflammation in Alzheimer's disease. Mt Sinai J Med 77, 50-58

16. Holmes C, Cunningham C, Zotova E et al (2009) Systemic inflammation and disease progression in Alzheimer disease. Neurology 73, 768-774

17. Leung R, Proitsi P, Simmons A et al (2013) Inflammatory proteins in plasma are associated with severity of Alzheimer's disease. PLoS One 8, e64971

18. Motta $M$, Imbesi R, Di Rosa $M$, Stivala $F$ and Malaguarnera L (2007) Altered plasma cytokine levels in Alzheimer's disease: correlation with the disease progression. Immunol Lett 114, 46-51

19. Dionisio-Santos DA, Olschowka JA and O'Banion MK (2019) Exploiting microglial and peripheral immune cell crosstalk to treat Alzheimer's disease. J Neuroinflammation 16,74

20. Dinarello CA and Wolff SM (1993) The role of interleukin-1 in disease. N Engl J Med 328, 106-113

21. Besedovsky $H$, del Rey A, Sorkin E and Dinarello CA (1986) Immunoregulatory feedback between interleukin-1 and glucocorticoid hormones. Science 233, 652-654

22. Shaftel SS, Griffin WS and O'Banion MK (2008) The role of interleukin-1 in neuroinflammation and Alzheimer disease: an evolving perspective. J Neuroinflammation 5, 7

23. Nicklin MJ, Weith A and Duff GW (1994) A physical map of the region encompassing the human interleukin-1 alpha, interleukin-1 beta, and interleukin-1 receptor antagonist genes. Genomics 19, 382-384

24. Allan SM, Tyrrell PJ and Rothwell NJ (2005) Interleukin-1 and neuronal injury. Nat Rev Immunol 5, 629-640

25. Patel HC, Boutin H and Allan SM (2003) Interleukin-1 in the brain: mechanisms of action in acute neurodegeneration. Ann N Y Acad Sci 992, 39-47

26. Griffin WS, Stanley LC, Ling C et al (1989) Brain interleukin 1 and S-100 immunoreactivity are elevated in Down syndrome and Alzheimer disease. Proc Natl Acad Sci U S A 86, 7611-7615

27. Sheng JG, Jones RA, Zhou XQ et al (2001) Interleukin-1 promotion of MAPK-p38 overexpression in experimental animals and in Alzheimer's disease: potential significance for tau protein phosphorylation. Neurochem Int 39, 341-348

28. Schneider $H$, Pitossi $F$, Balschun D, Wagner A, del Rey $\mathrm{A}$ and Besedovsky HO (1998) A neuromodulatory role of interleukin-1beta in the hippocampus. Proc Natl Acad Sci U S A 95, 7778-7783

29. Murray CA and Lynch MA (1998) Evidence that increased hippocampal expression of the cytokine interleukin-1 beta is a common trigger for age- and stress-induced impairments in long-term potentiation. J Neurosci 18, 2974-2981

30. Li Y, Liu L, Kang J et al (2000) Neuronal-glial interactions mediated by interleukin-1 enhance neuronal acetylcholinesterase activity and mRNA expression. J Neurosci 20, 149-155

31. Han SH, Park JC, Byun MS et al (2019) Blood acetylcholinesterase level is a potential biomarker for the early detection of cerebral amyloid deposition in cognitively normal individuals. Neurobiol Aging 73, 21-29

32. Su F, Bai F and Zhang Z (2016) Inflammatory Cytokines and Alzheimer's Disease: A Review from the Perspective of Genetic Polymorphisms. Neurosci Bull 32, 469-480

33. Mrak RE and Griffin WS (2000) Interleukin-1 and the immunogenetics of Alzheimer disease. J Neuropathol Exp Neurol 59, 471-476

34. Alvarez XA, Franco A, Fernandez-Novoa $\mathrm{L}$ and Cacabelos R (1996) Blood levels of histamine, IL-1 beta, and TNF-alpha in patients with mild to moderate Alzheimer disease. Mol Chem Neuropathol 29, 237-252

35. Licastro F, Pedrini S, Caputo L et al (2000) Increased plasma levels of interleukin-1, interleukin-6 and alpha-1-antichymotrypsin in patients with Alzheimer's disease: peripheral inflammation or signals from the brain? J Neuroimmunol 103, 97-102

36. De Luigi A, Pizzimenti S, Quadri P et al (2002) Peripheral inflammatory response in Alzheimer's disease and multiinfarct dementia. Neurobiol Dis 11, 308-314

37. Forlenza OV, Diniz BS, Talib LL et al (2009) Increased serum IL-1beta level in Alzheimer's disease and mild cognitive impairment. Dement Geriatr Cogn Disord 28, 507-512

38. Angelopoulos $\mathrm{P}$, Agouridaki $\mathrm{H}$, Vaiopoulos $\mathrm{H}$ et al (2008) Cytokines in Alzheimer's disease and vascular dementia. Int J Neurosci 118, 1659-1672

39. Italiani P, Puxeddu I, Napoletano S et al (2018) Circulating levels of IL-1 family cytokines and receptors in Alzheimer's disease: new markers of disease progression? J Neuroinflammation 15, 342

40. Lanzrein AS, Johnston CM, Perry VH, Jobst KA, King EM and Smith AD (1998) Longitudinal study of inflammatory factors in serum, cerebrospinal fluid, and brain tissue in Alzheimer disease: interleukin-1beta, interleukin-6, interleukin-1 receptor antagonist, tumor necrosis factoralpha, the soluble tumor necrosis factor receptors I and II, and alpha1-antichymotrypsin. Alzheimer Dis Assoc Disord 12, 215-227

41. Pirttila T, Mehta PD, Frey H and Wisniewski HM (1994) Alpha 1-antichymotrypsin and IL-1 beta are not increased in CSF or serum in Alzheimer's disease. Neurobiol Aging 15, 313-317

42. Yasutake $C$, Kuroda $K$, Yanagawa $T$, Okamura $T$ and Yoneda H (2006) Serum BDNF, TNF-alpha and IL-1beta levels in dementia patients: comparison between Alzheimer's disease and vascular dementia. Eur Arch Psychiatry Clin Neurosci 256, 402-406

43. Bonotis K, Krikki E, Holeva V, Aggouridaki C, Costa V and Baloyannis S (2008) Systemic immune aberrations in Alzheimer's disease patients. J Neuroimmunol 193, 183-187

44. Bauer J, Strauss S, Schreiter-Gasser U et al (1991) Interleukin-6 and alpha-2-macroglobulin indicate an acute-phase state in Alzheimer's disease cortices. FEBS Lett 285, 111-114

45. Huell M, Strauss S, Volk B, Berger M and Bauer J (1995) Interleukin-6 is present in early stages of plaque formation and is restricted to the brains of Alzheimer's 
disease patients. Acta Neuropathol 89, 544-551

46. Lee KS, Chung JH, Choi TK, Suh SY, Oh BH and Hong $\mathrm{CH}$ (2009) Peripheral cytokines and chemokines in Alzheimer's disease. Dement Geriatr Cogn Disord 28, 281-287

47. Sun YX, Minthon L, Wallmark A, Warkentin S, Blennow $\mathrm{K}$ and Janciauskiene $\mathrm{S}$ (2003) Inflammatory markers in matched plasma and cerebrospinal fluid from patients with Alzheimer's disease. Dement Geriatr Cogn Disord $16,136-144$

48. Wu YY, Hsu JL, Wang HC, Wu SJ, Hong CJ and Cheng IH (2015) Alterations of the Neuroinflammatory Markers IL-6 and TRAIL in Alzheimer's Disease. Dement Geriatr Cogn Dis Extra 5, 424-434

49. Singh VK and Guthikonda P (1997) Circulating cytokines in Alzheimer's disease. J Psychiatr Res 31, 657-660

50. Angelis P, Scharf S, Mander A, Vajda F and Christophidis N (1998) Serum interleukin-6 and interleukin-6 soluble receptor in Alzheimer's disease. Neurosci Lett 244, 106-108

51. van Duijn CM, Hofman A and Nagelkerken L (1990) Serum levels of interleukin-6 are not elevated in patients with Alzheimer's disease. Neurosci Lett 108, 350-354

52. Garlind A, Brauner A, Hojeberg B, Basun $\mathrm{H}$ and Schultzberg M (1999) Soluble interleukin-1 receptor type II levels are elevated in cerebrospinal fluid in Alzheimer's disease patients. Brain Res 826, 112-116

53. Tarkowski E, Liljeroth AM, Minthon L, Tarkowski A, Wallin A and Blennow K (2003) Cerebral pattern of proand anti-inflammatory cytokines in dementias. Brain Res Bull 61, 255-260

54. Richartz E, Stransky E, Batra A et al (2005) Decline of immune responsiveness: a pathogenetic factor in Alzheimer's disease? J Psychiatr Res 39, 535-543

55. Yamada K, Furusawa S, Saito K et al (1995) Concurrent use of granulocyte colony-stimulating factor with low-dose cytosine arabinoside and aclarubicin for previously treated acute myelogenous leukemia: a pilot study. Leukemia 9, 10-14

56. Papassotiropoulos A, Bagli M, Jessen F et al (1999) A genetic variation of the inflammatory cytokine interleukin- 6 delays the initial onset and reduces the risk for sporadic Alzheimer's disease. Ann Neurol 45, 666-668

57. Grimaldi LM, Casadei VM, Ferri C et al (2000) Association of early-onset Alzheimer's disease with an interleukin-1alpha gene polymorphism. Ann Neurol 47, 361-365

58. Nicoll JA, Mrak RE, Graham Dl et al (2000) Association of interleukin-1 gene polymorphisms with Alzheimer's disease. Ann Neurol 47, 365-368

59. Perry VH, Cunningham C and Holmes C (2007) Systemic infections and inflammation affect chronic neurodegeneration. Nat Rev Immunol 7, 161-167

60. Zhao M, Cribbs DH, Anderson AJ et al (2003) The induction of the TNFalpha death domain signaling pathway in Alzheimer's disease brain. Neurochem Res 28, 307-318

61. Lue LF, Walker DG and Rogers J (2001) Modeling microglial activation in Alzheimer's disease with human postmortem microglial cultures. Neurobiol Aging 22, 945-956

62. Janelsins MC, Mastrangelo MA, Park KM et al (2008) Chronic neuron-specific tumor necrosis factor-alpha expression enhances the local inflammatory environment ultimately leading to neuronal death in 3xTg-AD mice. Am J Pathol 173, 1768-1782

63. McAlpine FE and Tansey MG (2008) Neuroinflammation and tumor necrosis factor signaling in the pathophysiology of Alzheimer's disease. J Inflamm Res 1, 29-39

64. Brosseron F, Krauthausen $M$, Kummer $M$ and Heneka MT (2014) Body fluid cytokine levels in mild cognitive impairment and Alzheimer's disease: a comparative overview. Mol Neurobiol 50, 534-544

65. Tarkowski E, Blennow K, Wallin A and Tarkowski A (1999) Intracerebral production of tumor necrosis factor-alpha, a local neuroprotective agent, in Alzheimer disease and vascular dementia. J Clin Immunol 19, 223-230

66. Magaki S, Mueller C, Dickson C and Kirsch W (2007) Increased production of inflammatory cytokines in mild cognitive impairment. Exp Gerontol 42, 233-240

67. Bruunsgaard $\mathrm{H}$, Andersen-Ranberg $\mathrm{K}$, Jeune $\mathrm{B}$, Pedersen AN, Skinhoj P and Pedersen BK (1999) A high plasma concentration of TNF-alpha is associated with dementia in centenarians. J Gerontol A Biol Sci Med Sci 54, M357-364

68. Fillit H, Ding $W H$, Buee $L$ et al (1991) Elevated circulating tumor necrosis factor levels in Alzheimer's disease. Neurosci Lett 129, 318-320

69. Aliberti J, Reis e Sousa C, Schito M et al (2000) CCR5 provides a signal for microbial induced production of IL-12 by CD8 alpha+ dendritic cells. Nat Immunol 1, 83-87

70. Schulz O, Edwards AD, Schito $M$ et al (2000) CD40 triggering of heterodimeric IL-12 p70 production by dendritic cells in vivo requires a microbial priming signal. Immunity $13,453-462$

71. Chang HD and Radbruch A (2007) The pro- and anti-inflammatory potential of interleukin-12. Ann N Y Acad Sci 1109, 40-46

72. Rentzos M, Paraskevas GP, Kapaki E et al (2006) Interleukin-12 is reduced in cerebrospinal fluid of patients with Alzheimer's disease and frontotemporal dementia. J Neurol Sci 249, 110-114

73. Vom Berg J, Prokop S, Miller KR et al (2012) Inhibition of IL-12/IL-23 signaling reduces Alzheimer's disease-like pathology and cognitive decline. Nat Med 18, 1812-1819

74. Town T, Vendrame M, Patel A et al (2002) Reduced Th1 and enhanced Th2 immunity after immunization with Alzheimer's beta-amyloid(1-42). J Neuroimmunol 132, 49-59

75. te Velde AA, Huijbens RJ, Heije K, de Vries JE and Figdor CG (1990) Interleukin-4 (IL-4) inhibits secretion of IL- 1 beta, tumor necrosis factor alpha, and IL- 6 by human monocytes. Blood 76, 1392-1397

76. Gambi F, Reale M, larlori C et al (2004) Alzheimer patients treated with an AchE inhibitor show higher IL-4 
and lower IL-1 beta levels and expression in peripheral blood mononuclear cells. J Clin Psychopharmacol 24, 314-321

77. Lugaresi A, Di lorio A, larlori C et al (2004) IL-4 in vitro production is upregulated in Alzheimer's disease patients treated with acetylcholinesterase inhibitors. Exp Gerontol 39, 653-657

78. Strle K, Zhou JH, Shen WH et al (2001) Interleukin-10 in the brain. Crit Rev Immunol 21, 427-449

79. Fung TC, Olson CA and Hsiao EY (2017) Interactions between the microbiota, immune and nervous systems in health and disease. Nat Neurosci 20, 145-155

80. Kau AL, Ahern PP, Griffin NW, Goodman AL and Gordon JI (2011) Human nutrition, the gut microbiome and the immune system. Nature 474, 327-336

81. Kowalski K and Mulak A (2019) Brain-Gut-Microbiota Axis in Alzheimer's Disease. J Neurogastroenterol Motil $25,48-60$

82. Bonfili L, Cecarini V, Berardi S et al (2017) Microbiota modulation counteracts Alzheimer's disease progression influencing neuronal proteolysis and gut hormones plasma levels. Sci Rep 7, 2426

83. Arosio B, D'Addario C, Gussago C et al (2014) Peripheral blood mononuclear cells as a laboratory to study dementia in the elderly. Biomed Res Int 2014, 169203

84. Ziegler-Heitbrock L (2007) The CD14+ CD16+ blood monocytes: their role in infection and inflammation. J Leukoc Biol 81, 584-592

85. Ciccocioppo F, Lanuti P, Pierdomenico L et al (2019) The Characterization of Regulatory T-Cell Profiles in Alzheimer's Disease and Multiple Sclerosis. Sci Rep 9, 8788

86. Rezai-Zadeh K, Gate D, Szekely CA and Town T (2009) Can peripheral leukocytes be used as Alzheimer's disease biomarkers? Expert Rev Neurother 9, 1623-1633

87. Chen SH, Bu XL, Jin WS et al (2017) Altered peripheral profile of blood cells in Alzheimer disease: A hospitalbased case-control study. Medicine (Baltimore) 96, e6843

88. Lunnon K, Ibrahim Z, Proitsi P et al (2012) Mitochondrial dysfunction and immune activation are detectable in early Alzheimer's disease blood. J Alzheimers Dis 30, 685-710

89. Naert G and Rivest S (2013) A deficiency in CCR2+ monocytes: the hidden side of Alzheimer's disease. J Mol Cell Biol 5, 284-293

90. Richartz-Salzburger E, Batra A, Stransky E et al (2007) Altered lymphocyte distribution in Alzheimer's disease. J Psychiatr Res 41, 174-178

91. Aiyaz M, Lupton MK, Proitsi P, Powell JF and Lovestone S (2012) Complement activation as a biomarker for Alzheimer's disease. Immunobiology 217, 204-215

92. Kolev MV, Ruseva MM, Harris CL, Morgan BP and Donev RM (2009) Implication of complement system and its regulators in Alzheimer's disease. Curr Neuropharmacol 7, 1-8

93. Kamboh MI, Demirci FY, Wang X et al (2012) Genome-wide association study of Alzheimer's disease. Transl Psychiatry 2, e117
94. Kok EH, Luoto T, Haikonen S, Goebeler S, Haapasalo H and Karhunen PJ (2011) CLU, CR1 and PICALM genes associate with Alzheimer's-related senile plaques. Alzheimers Res Ther 3, 12

95. Bradt BM, Kolb WP and Cooper NR (1998) Complement-dependent proinflammatory properties of the Alzheimer's disease beta-peptide. J Exp Med 188, 431-438

96. Hakobyan S, Harding K, Aiyaz M et al (2016) Complement Biomarkers as Predictors of Disease Progression in Alzheimer's Disease. J Alzheimers Dis 54, 707-716

97. Weinstein G, Beiser AS, Preis SR et al (2016) Plasma clusterin levels and risk of dementia, Alzheimer's disease, and stroke. Alzheimers Dement (Amst) 3, 103-109

98. Williams MA, Haughton D, Stevenson M, Craig D, Passmore AP and Silvestri G (2015) Plasma Complement factor $\mathrm{H}$ in Alzheimer's Disease. J Alzheimers Dis 45, 369-372

99. Thambisetty M, Simmons A, Hye A et al (2011) Plasma biomarkers of brain atrophy in Alzheimer's disease. PLoS One 6, e28527

100. Haure-Mirande JV, Wang M, Audrain M et al (2019) Integrative approach to sporadic Alzheimer's disease: deficiency of TYROBP in cerebral Abeta amyloidosis mouse normalizes clinical phenotype and complement subnetwork molecular pathology without reducing Abeta burden. Mol Psychiatry 24, 431-446

101. Efthymiou AG and Goate AM (2017) Late onset Alzheimer's disease genetics implicates microglial pathways in disease risk. Mol Neurodegener 12, 43

102. Lambert JC, Heath S, Even G et al (2009) Genome-wide association study identifies variants at CLU and CR1 associated with Alzheimer's disease. Nat Genet 41, 1094-1099

103. Belbin O, Dunn JL, Chappell S et al (2008) A SNP in the ACT gene associated with astrocytosis and rapid cognitive decline in AD. Neurobiol Aging 29, 1167-1176

104. Toral-Rios D, Franco-Bocanegra D, Rosas-Carrasco O et al (2015) Evaluation of inflammation-related genes polymorphisms in Mexican with Alzheimer's disease: a pilot study. Front Cell Neurosci 9, 148

105. Morgan BP (2018) Complement in the pathogenesis of Alzheimer's disease. Semin Immunopathol 40, 113-124

106. Jin C, Li W, Yuan J, Xu W and Cheng Z (2012) Association of the CR1 polymorphism with late-onset Alzheimer's disease in Chinese Han populations: a meta-analysis. Neurosci Lett 527, 46-49

107. Liu G, Wang H, Liu J et al (2014) The CLU gene rs 11136000 variant is significantly associated with Alzheimer's disease in Caucasian and Asian populations. Neuromolecular Med 16, 52-60

108. Zhu R, Liu X and He Z (2018) Association between CLU gene rs11136000 polymorphism and Alzheimer's disease: an updated meta-analysis. Neurol Sci 39, 679-689

109. Tan L, Wang HF, Tan MS et al (2016) Effect of CLU genetic variants on cerebrospinal fluid and neuroimaging markers in healthy, mild cognitive impairment and 
Alzheimer's disease cohorts. Sci Rep 6, 26027

110. Xing YY, Yu JT, Cui WZ et al (2012) Blood clusterin levels, rs9331888 polymorphism, and the risk of Alzheimer's disease. J Alzheimers Dis 29, 515-519

111. Zhou J, Fonseca MI, Pisalyaput K and Tenner AJ (2008) Complement C3 and C4 expression in C1q sufficient and deficient mouse models of Alzheimer's disease. J Neurochem 106, 2080-2092

112. Fonseca MI, Chu S, Pierce AL et al (2016) Analysis of the Putative Role of CR1 in Alzheimer's Disease: Genetic Association, Expression and Function. PLoS One 11, e0149792

113. Foster EM, Dangla-Valls A, Lovestone S, Ribe EM and Buckley NJ (2019) Clusterin in Alzheimer's Disease: Mechanisms, Genetics, and Lessons From Other Pathologies. Front Neurosci 13, 164

114. Thambisetty M, Simmons A, Velayudhan L et al (2010) Association of plasma clusterin concentration with severity, pathology, and progression in Alzheimer disease. Arch Gen Psychiatry 67, 739-748

115. Jongbloed W, van Dijk KD, Mulder SD et al (2015) Clusterin Levels in Plasma Predict Cognitive Decline and Progression to Alzheimer's Disease. J Alzheimers Dis 46, 1103-1110

116. Winston CN, Goetzl EJ, Schwartz JB, Elahi FM and Rissman RA (2019) Complement protein levels in plasma astrocyte-derived exosomes are abnormal in conversion from mild cognitive impairment to Alzheimer's disease dementia. Alzheimers Dement
(Amst) 11, 61-66

117. Daborg J, Andreasson U, Pekna M et al (2012) Cerebrospinal fluid levels of complement proteins C3, C4 and CR1 in Alzheimer's disease. J Neural Transm (Vienna) 119, 789-797

118. Bennett S, Grant M, Creese AJ et al (2012) Plasma levels of complement 4a protein are increased in Alzheimer's disease. Alzheimer Dis Assoc Disord 26, 329-334

119. Yarchoan M, Louneva N, Xie SX et al (2013) Association of plasma C-reactive protein levels with the diagnosis of Alzheimer's disease. J Neurol Sci 333, 9-12

120. Locascio JJ, Fukumoto H, Yap L et al (2008) Plasma amyloid beta-protein and C-reactive protein in relation to the rate of progression of Alzheimer disease. Arch Neurol 65, 776-785

121. Watanabe Y, Kitamura K, Nakamura K et al (2016) Elevated C-Reactive Protein Is Associated with Cognitive Decline in Outpatients of a General Hospital: The Project in Sado for Total Health (PROST). Dement Geriatr Cogn Dis Extra 6, 10-19

122. Vintimilla R, Hall J, Johnson L and O'Bryant S (2019) The relationship of CRP and cognition in cognitively normal older Mexican Americans: A cross-sectional study of the HABLE cohort. Medicine (Baltimore) 98, e15605

123. Park JC, Han SH, Cho HJ et al (2017) Chemically treated plasma Abeta is a potential blood-based biomarker for screening cerebral amyloid deposition. Alzheimers Res Ther 9,20 